\title{
Análise das técnicas argumentativas nos textos dissertativo-argumentativos dos alunos do curso de redação PROENEM (UNILAB)
}

\author{
Leonardo Chaves Ferreira ${ }^{1}$, José Olavo da Silva Garantizado Júnior ${ }^{2}$
}

\begin{abstract}
Resumo: $O$ presente trabalho tem o objetivo de analisar como os estudantes pré-universitários do Curso de Redação Gratuito ProENEM, promovido pelo Projeto Palestras Interdisciplinares e Oficinas de Produção Textual para o ENEM (PROENEM), usam as técnicas argumentativas em redações dissertativo-argumentativas. Para darmos conta desse objetivo, a nossa base teórica está nos postulados de Perelman e Tyteca ([1958] 1996), sobre as técnicas argumentativas, Fiorin (2018), em sua investigação sobre a argumentação, em Garantizado Júnior (2015), em seu modelo de análise e descrição do fenômeno argumentativo sob uma perspectiva textual e retórica. Para este trabalho, analisamos 25 redações produzidas por 25 estudantes pré-universitários da Turma 1 do primeiro módulo do Curso de Redação. Nossos resultados apontam que, após intervenção didática do ProENEM, as técnicas argumentativas de comparação, exemplificação, vínculo causal, e referência à autoridade foram as mais utilizadas nos textos produzidos pelos pré-universitários com os quais realizamos a pesquisa.
\end{abstract}

Palavras-chave: Técnicas argumentativas. Nova retórica. Redação. ProENEM(UNILAB).

Área Temática: Educação.

\section{Analysis of the argumentative techniques in the dissertative-argumentative texts of the students of the PROENEM (UNILAB) writing course}

\begin{abstract}
This paper aims to analyze how the pre-university students of the ProENEM Free Writing Course, promoted by the Project Interdisciplinary Lectures and Textual Production Workshops for ENEM (PROENEM), use argumentative techniques in essay-argumentative essays. In order to realize this objective, our theoretical basis is in the postulates of Perelman and Tyteca ([1958] 1996), on argumentative techniques, Fiorin (2018), in his investigation of argumentation, in Garantizado Júnior (2015), in his model of analysis and description of the argumentative phenomenon from a textual and rhetorical perspective. For this work, we analyzed 25 essays produced by 25 pre-university students in Class 1 of the first module of the Writing Course. Our results point out that, after ProENEM didactic intervention, the argumentative techniques of comparison, exemplification, causal link, and reference to authority were the most used in the texts produced by the pre-university students with whom we conducted the research.
\end{abstract}

Keywords: Argumentative techniques. New rhetoric. Essay. ProENEM(UNILAB).

\footnotetext{
${ }^{1}$ Discente do curso de Letras - Língua Portuguesa da Universidade da Integração Internacional da Lusofonia Afro-Brasileira (UNILAB), bolsista do Programa de Educação Tutorial de Humanidades e Letras (PETHL/UNILAB) e pesquisador do Grupo de Pesquisa em Texto, Discurso e Ensino (TEDE/UNILAB).

${ }^{2}$ Professor do Programa de Pós-Graduação em Estudos da Linguagem da Universidade da Integração Internacional da Lusofonia Afro-Brasileira (PPGLin/UNILAB). Doutor e Mestre em Linguística pelo Programa de Pós-Graduação em Linguística da Universidade Federal do Ceará (PPGL/UFC).
} 


\section{Análisis de las técnicas argumentativas en los textos disertativo argumentativos de los alumnos del curso de escritura PROENEM(UNILAB)}

Resumen: Este artículo tiene como objetivo analizar cómo estudiantes preuniversitarios del Curso de Escritura Libre ProENEM, promovido por el Proyecto de Conferencias Interdisciplinarias y Talleres de Producción de Textos para ENEM (PROENEM), utilizan técnicas argumentativas en ensayos ensayo-argumentativos. Para realizar este objetivo, nuestra base teórica se encuentra en los postulados de Perelman y Tyteca ([1958] 1996), sobre técnicas argumentativas, Fiorin (2018), en su investigación de la argumentación, en Garantizado Júnior (2015), en su modelo de análisis y descripción del fenómeno argumentativo desde una perspectiva textual y retórica. Para este trabajo, analizamos 25 ensayos elaborados por 25 estudiantes preuniversitarios de la Clase 1 del primer módulo del Curso de Redacción. Nuestros resultados señalan que, tras la intervención didáctica del ProENEM, las técnicas argumentativas de comparación, ejemplificación, vínculo causal y referencia a la autoridad fueron las más utilizadas en los textos elaborados por los estudiantes preuniversitarios con los que realizamos la investigación.

Palabras clave: Técnicas argumentativas. Ensayo. Extensión. ProENEM(UNILAB).

\section{INTRODUÇÃO}

O Exame Nacional do Ensino Médio (ENEM) tem como objetivo, segundo o Portal do MEC ${ }^{1}$, avaliar o desempenho do estudante ao fim de sua escolaridade básica. Ele é aplicado desde 1998 e é utilizado como critério de seleção para os estudantes que desejam ingressar no Ensino Superior. A prova é dividida em dois dias, sendo composta por 180 questões e uma redação, que acontece no primeiro dia.

No ENEM, a redação é de caráter dissertativo-argumentativo, ou seja, o aluno deve defender uma tese, uma opinião a respeito do tema, baseada em argumentos sólidos e organizados de forma coesa e coerente, além de apresentar uma proposta de intervenção social para a solução de um problema. Segundo Medeiros (2010, p. 125): "Dissertar é apresentar ideias, analisá-las, é expor um ponto de vista [...]. Não basta narrar ou descrever; é necessário explanar e explicar". O texto dissertativo do ENEM exige justamente isto, a explicação do ponto de vista do aluno, através de uma argumentação estruturada e eficaz.

Observando os parâmetros de avaliação das redações do ENEM, percebemos a necessidade de produção de um texto que não deve analisar ineptamente um problema e, muito menos, expor uma série de ideias ou opiniões. Na verdade, o exigido permeia sobre um texto em que se discute um tema e se toma uma posição. É nessa perspectiva que, ao discutir sobre o papel da dissertação nos processos seletivos para as universidades, Therezo (2012) aponta que a tese deve ser sustentada por argumentos escolhidos com ordem e vigor; a coerência/ coesão deve garantir a clareza; o nível da linguagem deve obedecer às exigências da norma culta; e, por fim, a informatividade deve ser o recurso indispensável para se obter a adesão do leitor. Desse modo, o estudante deverá recorrer às diversas técnicas argumentativas para construir o seu posicionamento, organizando as informações de seu texto e selecionando dados suficientes para torná-lo atrativo e compreensível ao corretor, de forma a envolver o leitor, conduzindo-o à aceitabilidade da tese defendida.

No entanto, argumentar de forma estruturada e eficaz, no modelo proposto pelo ENEM, é desafiador para os pré-universitários. Os desafios são de várias ordens: da fidelidade ao tema proposto aos mecanismos 
que conferem coerência e coesão ao texto dissertativo-argumentativo. Segundo dados divulgados pelo Instituto Nacional de Estudos e Pesquisas Educacionais Anísio Teixeira (INEP²), o ENEM do ano de 2019 teve em torno de 143 mil participantes que zeraram a Prova de Redação. Esse balanço, divulgado pelo INEP no dia 17 de janeiro de 2020, revelou que um dos principais motivos causadores desses resultados negativos estava relacionado à fuga ao tema (40,624 participantes), dentre outros motivos, como redações em branco e cópias do texto motivador.

Tendo em vista essa questão, faz-se necessário pensar em ações práticas que possam reverter essa realidade, com o intuito de fornecer aos alunos pré-universitários um conjunto de conhecimentos que os possibilitam entender e desenvolver o texto dissertativo-argumentativo exigido pelo ENEM.

Nesse contexto são totalmente necessárias, dentro da Região do Maciço de Baturité, ações da Universidade da Integração Internacional da Lusofonia Afro-brasileira junto à comunidade a seu redor que disponibilizem o conhecimento adquirido por meio do ensino e da pesquisa desenvolvidos nos espaços acadêmicos. Uma dessas atividades é o Projeto Palestras Interdisciplinares e Oficinas de Produção Textual para o ENEM (PROENEM/UNILAB) que, no ano 2019, organizou o Curso de Redação Gratuito ProENEM, voltado ao desenvolvimento de palestras e recursos tecnológicos que permitissem o aperfeiçoamento da prática argumentativa e textual dos estudantes do Ensino Médio da Rede Pública de educação da Região do Maciço de Baturité.

Assim, este trabalho dedica-se à análise das técnicas argumentativas dos alunos que foram alcançados por esse projeto de extensão, com o objetivo de observar como esses estudantes constroem a argumentação em seus textos.

Nessa conjuntura, para darmos conta desse objetivo, nossa base teórica está nos postulados de Perelman e Tyteca ([1958] 1996), sobre as técnicas argumentativas no Tratado da Argumentação: Nova Retórica; de Fiorin (2018), em seus levantamentos sobre as questões relacionadas à argumentação e de Garantizado Júnior (2015) e Menezes (2011), em suas considerações sobre o fenômeno argumentativo em uma perspectiva textual e retórica. Metodologicamente, para realização deste trabalho, observamos a dinâmica das oficinas da Turma 1 do Curso de Redação Gratuito do projeto de extensão PROENEM/UNILAB e, a partir da produção textual dos alunos, formamos o corpus da pesquisa.

A relevância do nosso trabalho está, especialmente, na análise das técnicas argumentativas dos alunos que tiveram acesso a um projeto de extensão universitária. Temos o conhecimento de que extensão se credencia, cada vez mais, junto à sociedade, como espaço privilegiado de produção do conhecimento significativo para a superação das desigualdades sociais existentes. Em nosso caso, o oferecimento de um curso de redação gratuito aos alunos da Rede Pública busca aproximar a prática acadêmica à comunidade, aliando os níveis de ensino, pesquisa e extensão, na superação de problemas que por muitas vezes distanciam a universidade da realidade dos pré-universitários da escola pública. 
Em termos de organização, nosso trabalho está dividido da seguinte maneira: inicialmente, discorremos sobre a Nova Retórica, de Perelman e Tyteca ([1958] 1996), focando na categorização das Técnicas Argumentativas. Depois, partimos para a análise do corpus, investigando a maneira como os estudantes préuniversitários do Curso Redação usaram as técnicas argumentativas.

\section{OBJETIVOS}

O nosso trabalho se dedica à análise das técnicas argumentativas dos alunos que participaram do Curso de Redação ProENEM (UNILAB), no propósito de observar como esses estudantes que participaram de um projeto de extensão universitária passaram a construir argumentação em seus textos.

\section{METODOLOGIA}

Na realização deste trabalho, tivemos a oportunidade de observar a dinâmica das oficinas da Turma 1 do Curso de Redação Gratuito do projeto de extensão PROENEM/UNILAB, realizado nas dependências da Universidade da Integração Internacional da Lusofonia Afro-Brasileira (Redenção-CE), entre os meses de fevereiro a outubro de 2019. Os recursos metodológicos utilizados nas oficinas eram confeccionados pelos próprios integrantes voluntários e sua aplicação nas atividades do curso também era efetuada pelos oficineiros. Além disso, entramos em contato com o material usado nas aulas, as propostas de redação indicadas nas oficinas e os textos produzidos pelos estudantes pré-universitários. O Módulo do qual participamos teve um total de 5 aulas, ministradas para três turmas, em três diferentes horários, durante os meses de maio e junho de 2019. Cabe ressaltar que, para a divisão dos assuntos a serem abordados nas aulas, antes da realização do Curso de Redação, a equipe PROENEM/UNILAB promoveu simulados de Redação nas escolas do Maciço de Baturité para diagnosticar os principais problemas dos estudantes e, a partir dos textos, preparar as oficinas com foco interventivo.

Com a correção desses simulados, a equipe de correção do Projeto PROENEM/UNILAB, junto com o Grupo de Estudos em Texto, Discurso e Ensino (TEDE/UNILAB), verificou algumas dificuldades presentes na maioria dos textos dos estudantes de escolas públicas do Maciço de Baturité: deficiências na estrutura textual dissertativo-argumentativa, problemas no desenvolvimento de uma tese consistente e sérias dificuldades no repertório argumentativo dos textos.

A partir dessa verificação, as aulas do Curso dividiram-se em cinco: duas relacionadas à estrutura do texto dissertativo-argumentativo e três voltadas inteiramente às técnicas argumentativas na redação estilo ENEM, focando principalmente nos argumentos por comparação, exemplo, causa e consequência e autoridade.

Após a realização das oficinas e a partir do contato com os textos produzidos pelos estudantes préuniversitários, iniciamos o processo de construção do corpus. Para isso, o critério usado foi a assiduidade da Turma 1 do Curso de Redação, composta por 25 estudantes pré-universitários que participaram 
ativamente das ações desenvolvidas no Curso. Selecionamos, então, 25 redações desenvolvidas durante as atividades finais do Curso sobre os temas "Bullying Escolar", "Violência Infantill" e "Violência com a população idosa".

Cada redação recebeu uma codificação específica para que a identidade dos informantes fosse preservada, como por exemplo RED2019C01: a) as três primeiras letras significam o tipo de texto (RED- Redação); b) os quatro números seguintes significam o ano da produção do texto (2019); c) a letra "C" significa que a ação de extensão resultante do texto (no caso, Curso de Extensão) e d) os dois números finais significam a sequência em que o texto foi digitalizado pelo projeto (01).

Como mencionado anteriormente, participamos das atividades do projeto, tendo acesso ao material elaborado pelos oficineiros e aos textos produzidos pelos alunos, a fim de averiguarmos o processo de construção da argumentação e mapearmos as principais técnicas argumentativas utilizadas.

\section{RESULTADOS E DISCUSSÃO}

\section{A Nova Retórica e as Técnicas Argumentativas}

A Nova Retórica constitui uma teoria da Argumentação proposta por Chaïm Perelman e OlbrechtsTyteca, sob o título de Tratado da Argumentação - a Nova Retórica. Esse Tratado, segundo Garantizado Júnior (2015), apresenta uma ligação íntima com a retórica clássica, mas, como aponta Rodriguez (2017), traz também uma diferença, por fazer uma ligação da retórica à pragmática de valores, ao invés de estar ligada à noção de verdade proposicional da antiga retórica. Desse modo, Perelman e Tyteca ([1958] 1996) propõem um novo modo de lidar com a argumentação, buscando a compreensão dos discursos verossímeis.

O que norteia o trabalho de Perelman e Tyteca é a reconstrução de uma teoria da argumentação que esteja em conformidade com os diversos tipos de discurso. Dessa forma, com base nos fundamentos da Antiga Retórica e defendendo que a argumentação surge em uma situação de conflito através de teses antagônicas, o autor e a autora especificam uma tipologia de auditórios e de argumentos.

Nesse sentido, a partir do Componente Retórico da Argumentação, defendido por Garantizado Júnior (2015), voltamos o foco deste trabalho para as técnicas argumentativas, elementos capazes de justificar e provar os argumentos do locutor. Concordamos, então, com Rodriguez (2017), ao afirmar que a grande contribuição do Tratado para os estudos sobre o fenômeno argumentativo é o legado inventário de técnicas argumentativas que, na obra, se apresentam organizadas em argumentos de ligação e de dissociação. Dos esquemas de ligação, caracterizados pela aproximação entre elementos distintos e foco deste trabalho, fazem parte os seguintes tipos de argumentos: (1) argumentos quase-lógicos; (2) argumentos fundados na estrutura do real; (3) argumentos que fundamentam a estrutura do real. O quadro seguinte apresenta de forma resumida as técnicas argumentativas postuladas por Perelman e Tyteca ([1958] 1996): 
Quadro 1 - Classificação dos argumentos de acordo com a Nova Retórica

\begin{tabular}{|l|l|}
\hline \multirow{2}{*}{ Argumentos quase lógicos } & $\begin{array}{l}\text { - Reciprocidade; - Transitividade; - Inclusão e divisão; } \\
\text { - Regra de justiça; - Comparação; - Sacrifício; } \\
\text { - Tautologia;- Probabilístico; - Definição. }\end{array}$ \\
\hline $\begin{array}{l}\text { Argumentosbaseados } \\
\text { na estrutura do real }\end{array}$ & $\begin{array}{l}\text { - Relação de sucessão (causal, pragmático, } \\
\text { desperdício, direção,superação); } \\
\text { - Relação de coexistência (pessoa-ato, autoridade, } \\
\text { hierarquia, grau e ordem). }\end{array}$ \\
\hline $\begin{array}{l}\text { Argumentos quefundam } \\
\text { aestrutura do real }\end{array}$ & $\begin{array}{l}\text { - Fundamentação por um caso particular (exemplo, } \\
\text { ilustração,modelo);- Fundamentação por } \\
\text { analogia ou metáfora. }\end{array}$ \\
\hline
\end{tabular}

Fonte: Elaborado a partir de Rodriguez (2017) com dados extraídos de PERELMAN; TYTECA, 2014.

Ao propormos a análise das redações produzidas no cursinho pré-vestibular do ProENEM (UNILAB), pretendemos descrever como as técnicas argumentativas citadas acima são usadas pelos estudantes préuniversitários. De modo geral, essas técnicas argumentativas são mecanismos que utilizamos para a apresentação de nossos argumentos, algo que é comum em redações estilo ENEM, já que os critérios exigem do autor a apresentação de argumentos em defesa do seu ponto de vista. Para a análise das técnicas argumentativas dos estudantes pré-universitários do curso de Redação Gratuito do Projeto de Extensão ProENEM (UNILAB), nos baseamos, principalmente, na terceira parte do livro Tratado da argumentação: A Nova Retórica (PERELMAN; TYTECA, [1958] 1996).

Dessa maneira, iniciamos nossas discussões pelos argumentos baseados na estrutura do real. Eles surgem a partir da realidade e, assim, estabelecem uma ligação entre o real e os valores que se buscam admitir. Esses argumentos baseiam-se em expor "opiniões quanto ao que se considera real” (MENEZES, 2011, p. 122), isto é, se sustentam a partir daquilo que nós, particularmente, consideramos como verdadeiro no mundo objetivo. Fazem parte dessa categoria os argumentos de autoridade, por desperdício, direção, superação, vínculo causal e o pragmático. Dentro desses argumentos, destacamos, primeiramente, o de autoridade, que, nas redações, caracteriza-se por citações diretas e indiretas. Assim, o pré-universitário sustenta o seu ponto de vista a partir do discurso de um pensador ou escritor renomado em torno do tema. Ao falar dessa estratégia argumentativa, Perelman e Tyteca ([1958] 1996, p. 348) salientam que nessa técnica temos a utilização de "atos ou juízos de uma pessoa ou de um grupo de pessoas como meio de prova a favor de uma tese", isso porque certos juízos de um insigne orador acabam funcionando como um bom argumento favorável a uma determinada proposição.

Já o argumento pelo desperdício é uma técnica em que se propõe a continuação de uma determinada atitude, ação ou escolha, tendo em vista o não desperdício dos esforços que já foram feitos. Para explicar essa técnica, Fiorin (2018) ressalta que ela é voltada ao passado, reforçando o raciocínio de que não se deve jogar fora o que já se fez. De acordo com Perelman e Tyteca ([1958] 1996), existe ainda uma outra técnica que 
funciona a partir da decomposição de um determinado objetivo (fim) em um conjunto de etapas. Para explicar essa técnica, Menezes (2011) mostra que esse argumento, o argumento de direção, responde à pergunta: aonde se quer chegar? Nesse sentido, esse argumento toma o procedimento adotado nas etapas para a formação de um argumento positivo contra uma determinada ação fatal na busca por uma meta.

Ainda dentro desses argumentos baseados na estrutura do real, temos, em conformidade com os levantamentos da Nova Retórica ([1958] 1996), um argumento que sempre insiste na possibilidade de ir além em um certo sentido ou objetivo. Essa técnica argumentativa é chamada de recurso à superação e, sendo um argumento voltado para o futuro, considera que a meta alcançada é uma etapa para se chegar a um outro estágio superior.

Falando do argumento de vínculo causal, ou de causalidade, podemos notar que ele se explicita de modo a deixar claro que um determinado evento é produto de algo que lhe foi antecedente. Perelman e Tyteca ([1958] 1996), ao falarem da relação entre os vínculos casuais e a argumentação, destacam dois modos pelos quais esse tipo de argumento se expressa, e esse fato deixa notória a variedade dos efeitos que essa estratégia tem capacidade de produzir. O primeiro, que "dado um acontecimento, tendem a descobrir a existência de uma causa que pode determiná-lo" (PERELMAN; TYTECA, [1958] 1996, p. 299); e o segundo, que "dado um acontecimento, tendem a evidenciar o efeito que dele deve resultar" (PERELMAN; TYTECA, [1958] 1996 p. 300). Desse modo, concordamos com Lima et al. (2018 p. 126), ao afirmarem que o acontecimento envolvido dentro desse argumento "pode apresentar interpretação diferenciada conforme a ideia que se forma".

O argumento pragmático, por sua vez, "permite apreciar um ato ou um acontecimento consoante suas consequências favoráveis ou desfavoráveis" (PERELMAN; TYTECA, [1958] 1996), p. 299). Essa técnica argumentativa consiste em avaliar um ato a partir de suas possíveis consequências. Garantizado Júnior (2015 p. 185) ressalta que esses argumentos são capazes de acontecer sem a pretensão do locutor e, dentro dessas condições, "podem ocorrer sem dificuldades, já que as transferências, para a causa, do valor para as consequências, ocorrem sem problemas".

As ligações que fundamentam a estrutura do real, por seu turno, são divididas em dois tipos: o fundamento pelo caso particular e o raciocínio por analogia. Nesse sentido, o primeiro se relaciona com argumentos baseados na estrutura do real e não está ligado a uma descrição objetiva dos fatos, mas a pontos de vista relativos (particulares) a eles. Já o segundo é caracterizado "como uma similitude de relações entre termos pertencentes a áreas diferentes" (MENEZES, 2011, p. 61), ou seja, é uma semelhança entre conteúdos que pertencem a planos distintos. Perelman e Tyteca ([1958] 1996) destacam a importância da analogia, por não a considerarem diferente de nenhum outro raciocínio, e oferecem a fórmula para a "similitude de estruturas", em que A está para B, assim como C está para D.

Dessa forma, destacamos, dentro dos argumentos que fundam a estrutura do real, o argumento por ilustração e pelo recurso ao exemplo. Ambas as técnicas caracterizam-se pela presença de argumentos que recorrem a casos particulares, ou seja, a primeira técnica tem como objetivo a ilustração de casos particulares 
que evidencia uma tese defendida e a segunda generaliza ocorrências a partir de casos particulares. Assim, conforme afirmam Lima et al. (2018), a ilustração, tendo em vista o caso particular, objetiva a concretude de uma regra abstrata. Já no recurso ao exemplo, conforme os postulados de Perelman e Tyteca ([1958] 1996), o locutor tenta apresentar o exemplo particular com o objetivo de estabelecer no auditório certas conclusões. É nesse sentido que o argumento pelo exemplo busca a generalização de um fato, baseando-se em casos particulares.

Por seu turno, os argumentos quase lógicos caracterizam-se por se tratar de argumentos que buscam construir a persuasão a partir de "raciocínios formais, lógicos ou matemáticos" (MENEZES, 2011, p. 121). As técnicas envolvidas nesse tipo de argumento apresentam um aspecto demonstrativo, ou seja, possuem sua força argumentativa a partir de juízos preferíveis em que a conclusão é "provável, possível, plausível, mas não logicamente necessária" (FIORIN, 2018, p. 115).

O primeiro argumento quase-lógico que destacamos é o de comparação que, de forma geral, está ligado a um efeito de avaliação de A em relação B. Desse modo, esse argumento tem como objetivo relacionar objetos com uma ideia de mediação que pode reforçar tanto uma desigualdade quanto uma igualdade. Segundo Perelman e Tyteca ([1958] 1996), os modos de avaliação advindos das comparações podem ocorrer por oposição, por ordenamento e por ordenação quantitativa.

Os mesmos autores ainda consideram um outro argumento como um argumento quase-lógico por se aproximar da comparação. Nele, se busca comprovar a veracidade de uma tese por meio do sacrifício de alguém, ou seja, baseia-se em um sacrifício que se está disposto a fazer, tendo em vista a obtenção de um resultado. Segundo Menezes (2011), esse argumento, argumento do sacrifício, também pode ser usado de forma hipotética, evidenciando o valor que se dá a algo. Sendo assim, essa técnica argumentativa destaca a valoração concedida a algo ou a alguém como central para que se adote uma determinada ação.

Uma outra técnica argumentativa que devemos considerar, dentro dessa categoria de argumentos, caracteriza-se por ser um tipo de raciocínio em que o predicado, aparentemente, parece não agregar informações ao sujeito. Essa técnica é chamada de tautologia e acontece em teses que defendem, por exemplo, que "professor é professor!”. Nessas ocorrências é possível identificar que o primeiro termo não tem o mesmo sentido do segundo, isso quer dizer que esses tipos de expressões são quase-lógicas porque "no início, tratamos os termos como suscetíveis [...], mas, após a interpretação, surgem diferenças” (MENEZES, 2011, p.41).

A terceira técnica que pode ser abordada em nossas análises refere-se ao argumento por definição que, de acordo com Perelman e Tyteca ([1958] 1996), são definições diferentes de um mesmo termo em uma língua natural que mostram a característica argumentativa das próprias definições. Não há uma maneira unívoca de definir um objeto, sendo possível defini-lo por suas características composicionais ou pela função que é capaz de desempenhar. Ao discutir essa estratégia, Menezes (2011, p. 41) ressalta: "Elas tanto podem ser justificadas, com a ajuda de argumentos, como podem, em sem si mesmas, ser argumentos", isso porque as definições são orientadas ao convencimento do interlocutor para que ele tome determinado significado como aquele que deve ser levado em conta. 
Há, ainda, uma técnica argumentativa construída a partir da apresentação de um raciocínio em que elementos ou situações de uma mesma classe devem receber tratamento igualitário. Esse argumento, chamado de regra de justiça, segundo Perelman e Tyteca ([1958] 1996), só poderá configurar uma demonstração rigorosa quando os objetos envolvidos forem totalmente intercambiáveis, ou seja, idênticos. Assim sendo, essa técnica argumentativa fundamenta-se no tratamento idêntico a seres ou situações integrados em uma mesma categoria. Da mesma forma, a reciprocidade, quando utilizada na argumentação, designa um argumento quase-lógico, por um princípio de correspondência. Segundo Perelman e Tyteca ([1958] 1996), essa é uma técnica argumentativa que visa estabelecer o mesmo tratamento a duas situações correspondentes, como uma equivalência: “A está para B assim como B está para A”. Nesse contexto, conforme Fiorin (2018), os argumentos baseados em um princípio de reciprocidade são aqueles que colocam o enunciatário no lugar de alguém, mostrando que se o interlocutor estivesse no lugar de um terceiro, não agiria diferente.

É importante também ressaltarmos o argumento por inclusão da parte no todo. Essa técnica argumentativa caracteriza-se pela consideração de que uma parte possui as mesmas características de um todo. Logo, o que vale para o todo vale para as partes, ou seja, analisam-se apenas relações que possibilitam uma comparação quase que matemática, o que possibilita argumentações que se baseiam no raciocínio citado anteriormente. De modo diferente, o argumento pela divisão do todo em suas partes, segundo Perelman e Tyteca ([1958] 1996), já acontece na formulação de hipóteses e raciocínios que atribuem uma propriedade de cada parte ao todo, ou seja, o que vale para as partes também vale para o todo. Já uma outra técnica compete ao que Fiorin (2018) chama de argumento probabilístico. Essa estratégia leva em consideração aspectos mais estatísticos que possibilitam a sustentação aparentemente plausível de um argumento, pois, estando fundada no princípio da não contradição, toma como verdade a proposição sustentada pela maioria que, sendo numérica (em nosso caso), entra em contradição com o juízo defendido pela minoria, avaliado como falso ou menos certo.

De modo geral, podemos dizer que essas técnicas argumentativas aqui mencionadas estão ligadas ao modo como o orador justifica ou contesta posicionamentos. Dessa forma, concordando com o que Lima et al. (2018 p. 128) defendem, acreditamos que as técnicas argumentativas mostram o grau de "engajamento do sujeito na linguagem por meio da persuasão", ou seja, o objetivo maior será, sempre, discutir os temas, demonstrar repertório e apresentar um posicionamento, justificado, a respeito do assunto. Assim, partindo desse levantamento teórico feito, na próxima seção iremos analisar e discutir os argumentos utilizados nas redações produzidas pela turma 01 do Curso de Redação Gratuito ProENEM/UNILAB.

\section{Análise dos Resultados}

Para a análise, nos debruçamos sobre os textos dissertativos-argumentativos dos alunos do Curso de Redação ProENEM/UNILAB que participaram das oficinas sobre redação e técnicas argumentativas oferecidas pelo projeto. Nos textos, produzidos durante a realização das oficinas finais do Curso, observamos uma diversidade 
de argumentos definidos na abordagem teórica da Nova Retórica (PERELMAN; TYTECA, 2016). Um exemplo disso é a argumentação a partir do vínculo causal, que se baseia na relação de um fato com sua consequência. Para Perelman e Tyteca (2016), esse tipo de argumentação, sendo fundada na estrutura do real, consiste na valorização dada a um determinado acontecimento de acordo com as suas consequências. Isso ficou evidente no exemplo a seguir:

(1) Outro grave problema é o abandono dos estudos por parte dos jovens, que por estarem sujeitos a agressões como a negligência, o abandono e o próprio trabalho infantil, acabam por desacreditar em um futuro melhor proporcionado pelos estudos (RED2019C01).

Em (1), o locutor sustenta a tese de que o abandono escolar, como consequência de condições sociais desfavoráveis, existe por causas maiores, como a negligência, o abandono e o trabalho infantil. Nessa estratégia, o pré-universitário explicita um acontecimento, que é o abandono dos estudos, e a existência de uma causa que pode determiná-lo, no caso, a negligência. Do mesmo modo, no exemplo que segue, é possível observar essa estratégia argumentativa na tese de que um acontecimento anterior produz um determinado efeito de acordo com as consequências dele resultante:

(2) Os principais motivos causadores do bullying estão, por muitas vezes, ligados ao preconceito da parte do agressor em relação a vítima, podendo ser religioso, aparência física, sotaque, orientação sexual, lugar de origem etc. Tendo como consequência a depressão, afetando também a relação da vítima com o meio social, ocasionando em alguns casos o suicídio da pessoa afetada. (RED2019C02).

Em (2), basicamente, conseguimos observar que o estudante pré-universitário sustenta a tese de que a depressão, como consequência do bullying, produz um determinado efeito que tem por causa maior os preconceitos praticados pelo agressor. Desse modo, temos um dado acontecimento e a evidência do efeito que ele resulta, $o$ que mostra mais um modo pelo qual o argumento de causalidade pode ser expresso. No fragmento seguinte temos esse mesmo tipo de ocorrência:

(3) A intolerância e a falta de empatia com relação ao outro são primórdios do que futuramente vem por se tornar, agressões que afetam drasticamente a vida da vítima de modo geral. (RED2019C04).

No exemplo (3), o estudante pré-universitário elenca certas atitudes e os efeitos que elas podem resultar. A expressão nominal “vem por se tornar", que indica um processo de modificação em que objeto passa a possuir uma nova condição, evidencia a utilização dessa estratégia por causa e consequência. Assim, o préuniversitário aponta a intolerância e a falta de empatia como atitudes que colaboram para que as agressões aconteçam, ou seja, um fato causador (as atitudes) e o seus resultados (as agressões). 
Nas redações produzidas no Curso também encontramos uma outra técnica argumentativa que, segundo Fiorin (2018), está fundada em uma "lógica quantitativa”. Nessa perspectiva, essa estratégia traz consigo um atributo numérico, como no exemplo abaixo:

(4) De acordo com uma pesquisa realizada pelo G1, aproximadamente $20 \%$ dos alunos afirmaram ter praticado bullying em algum momento da vida e cerca de $34,8 \%$ dos entrevistados disseram ter sofrido agressões físicas e psicológicas devido a sua aparência. Deixando notório que o nível de exclusão por esse ato é absurdo [...] (RED2019C03).

Em (4), o estudante pré-universitário faz uso do argumento probabilístico para defender a tese de que o bullying, sendo recorrente, deve ser combatido. Aargumentação nesse fragmento consiste em mostrar que muitas pessoas ainda praticavam e sofriam bullying e, desse modo, faz-se necessário combater esse tipo de atitude, renunciando a um sistema ruim, em favor de um sistema mais vantajoso (PERELMAN; TYTECA, [1958] 1996).

Outro tipo de argumento levantado em nossas considerações, com base nos achados de Perelman e Tyteca ([1958] 1996), consiste nas definições de um termo da língua, o que deixa claro como o modo de definir é dependente das finalidades argumentativas. Segundo Fiorin (2018), os argumentos por definição se orientam para um convencimento do interlocutor sobre determinado significado que deve ser considerado, por isso, são quase-lógicos e se orientam dentro do princípio da identidade. Essa estratégia argumentativa tornou-se notória no exemplo a seguir:

(5) Com similaridade ao passado, o Brasil em seus âmbitos escolares ainda possui jovens que agridem física e verbalmente pessoas com determinados tipos de diferenças, sejam elas estéticas ou físicas, ocorrendo, consequentemente, o processo de exclusão, denominado atualmente como bullying. Nos meios educacionais brasileiros, esse ato é uma realidade, no entanto ainda há dificuldades para que o impasse seja resolvido. (RED2019C11).

Em (5), a definição de "bullying" dada pelo estudante desempenha um objetivo argumentativo, pois coopera com a sua tese de que essas ocorrências fazem parte da realidade do sistema educacional brasileiro e existem adversidades quanto às formas de se combater esse problema. A presença desse argumento em temas que envolvem conceitos pertinentes na sociedade, como "Bullying" e "Fake News", é bastante frequente, pois o pré-universitário vê a necessidade de argumentar a partir da definição de um conceito central do tema de sua redação. Faz-se interessante observarmos que, em determinados contextos, podemos ter diferentes definições de um mesmo objeto, por um motivo argumentativo. Uma outra ocorrência dessa mesma estratégia argumentativa encontramos em (6):

(6) A intolerância e a falta de empatia com relação ao outro são primórdios do que futuramente vem por se tornar, agressões que afetam drasticamente a vida da vítima de modo geral. A palavra "bullying" refere-se justamente a essas agressões, realizadas de forma contínua e intencional destinadas a um grupo ou a um único indivíduo. (RED2019C03). 
No exemplo (6), assim como no anterior, temos uma definição de bullying que faz referência ao mecanismo da agressão. Mas, diferentemente do exemplo (5), em que o bullying também é encarado como um processo de “exclusão social”, a definição de bullying feita em (6) prioriza somente a agressão física, pois a estrutura argumentativa do parágrafo começa, justamente, pela evidência de causas que trazem como consequência as agressões que geram e definem o conceito “bullying”. Dessa forma, podemos notar que o modo de definir pode não ser o mesmo a depender da finalidade argumentativa.

Existem também outras formas de definir, como aproximar ou distanciar um objeto de outro, tendo em vista as características e funções desses objetos. Quando fazem isso, muitas vezes em uma tentativa de estabelecer uma similitude entre fatos e acontecimentos, os estudantes estabelecem o argumento por comparação, como no exemplo abaixo:

(7) Durante o período da Segunda Guerra Mundial (1939-1945), Adolf Hettler, considerava os "arianos" a raça pura da Alemanha, excluindo judeus e negros de seus direitos como cidadãos. Com similaridade ao passado, o Brasil em seus âmbitos escolares ainda possui jovens que agridem física e verbalmente pessoas com determinados tipos de diferenças, sejam elas estéticas ou físicas [...]." (RED2019C012).

Em (7), o estudante busca estabelecer uma semelhança que fortalece a sua argumentação. Ele faz uma comparação entre o regime nazista e o bullying nas escolas brasileiras, aproximando os aspectos segregacionistas de ambas as práticas. É importante ressaltar que, segundo Fiorin (2018), esse tipo de argumento, por assimilar "aspectos acidentais do objeto" pode deixar de lado algumas diferenças que são primordiais, pois, apesar de os objetos possuírem valores de semelhança, eles não serão idênticos, ao variar pela "finalidade, pelas forças sociais que os sustentam, pelo gênero de sociedade em que se desenvolveram etc.” (FIORIN, 2018, p. 124). Comumente, os alunos do Curso utilizam esse tipo de técnica argumentativa em suas redações, realizando comparações entre épocas, situações, locais, atribuindo um valor de similaridade ou disparidade entre os elementos de sua argumentação. Desse modo, usam a semelhança para justificar o ponto de vista abordado na tese.

Como falamos anteriormente, no tópico dedicado à explicitação das técnicas argumentativas, na abordagem teórica da Nova Retórica, de Perelman e Tyteca ([1958] 1996), temos os argumentos fundados na estrutura do real. Observando o nosso corpus, que constitui as redações produzidas durante o curso, essa categoria de argumentos foi profusamente usada pelos estudantes pré-universitários. O recurso a uma autoridade como estratégia de argumentação, por exemplo, é fundado na estrutura do real. Ele consiste, segundo Perelman e Tyteca ([1958] 1996), em relações de prestígio, na utilização de juízos de outras pessoas como forma de provar uma tese. Essa técnica se mostrou evidente no exemplo a seguir:

(8) Ademais, segundo Benedetto Croce, “A violência jamais poderá ser criadora de coisa alguma, apenas destruidora”, fazendo-se evidente de que o bullying em nenhum momento será solução para a maneira como o ser humano se vê perante aos outros indivíduos. (RED2019C01). 
Em (8), podemos constatar que o pré-universitário usa a autoridade de Benedetto Croce, filósofo, historiador e político italiano, para argumentar que atos de violência, como o bullying, promovem apenas um regresso agressivo na sociedade. Nesse tocante, o estudante se vale da autoridade que enuncia para defender a tese de que o bullying, sendo uma "violência destruidora", não é justificativa para defender o modo como o indivíduo se enxerga diante dos outros. Essa técnica argumentativa, segundo Fiorin (2018), exige que o ponto de vista da autoridade se mostre plausível dentro da tese. Vejamos, então, mais um exemplo:

(9) De acordo com o filósofo Immanuel Kant, o homem é o que é devido a sua educação. Relacionando com o Brasil, o governo deveria investir bem mais na educação para evitar uma cultura de casamentos precoces, ameaças online e a própria violência sexual estabelecendo ordem e limites para se ter uma sociedade melhor. (RED2019C01).

Em (9), a argumentação consiste na ideia, quase que comum, de que a educação é um fator preponderante para o aferimento dos principais índices oficiais de desenvolvimento de um determinado país. Logo, o investimento na educação levaria o país à prosperidade e evitaria condições de vulnerabilidade social, como a "violência sexual", tema da redação de nosso estudante. Nesse caso, mais uma vez, o pré-universitário se vale da citação indireta de um terceiro que, sendo amplamente considerado como o principal filósofo da era moderna, fundamenta a sua tese, pois se "o homem não é nada além daquilo que a educação faz dele", deve-se investir em educação para evitar-se os diversos tipos de violência social.

O argumento pelo "recurso ao exemplo", também estruturado na realidade, consiste, segundo Perelman e Tyteca ([1958] 1996), na busca por uma generalização a partir de casos particulares, ou seja: "O Locutor tenta apresentar um exemplo particular com o objetivo de estabelecer no auditório certas conclusões" (GARANTIZADO JÚNIOR, 2015, p. 197). No nosso caso, é comum que os estudantes recorram ao exemplo para fundamentar afirmações, regras e/ou generalizações, como no fragmento que segue:

(10) Talvez seja difícil dizer o real motivo pelo qual esses bullyings nas escolas vêm ocorrendo, mas é certeza dizer que uma pessoa que sofre bullying por muito tempo, se não tiver ajuda, nunca mais voltará a ser a mesma. Como exemplo, o caso da escola em Suzano, de dois jovens que por terem sofrido bullying, talvez por muito tempo, acabaram tirando a vida de pessoas inocentes e depois tirando suas próprias vidas. (RED2019C03).

Em (10), pode-se averiguar que o estudante pré-universitário utiliza o exemplo do massacre ocorrido em Suzano (SP), no ano de 2019, para justificar a sua tese de que o bullying, ao acontecer por um longo período, pode afetar emocionalmente e psicologicamente as vítimas. Desse modo, generaliza-se um acontecimento tendo em vista uma determinada conclusão. O acontecimento do massacre em Suzano (SP) também é utilizado na redação seguinte: 
(11) Fazendo-se uma análise das tragédias acontecidas atualmente, por "vingança" das vítimas, como no caso do massacre da escola em São Paulo, caso que ocasionou a morte de várias crianças. É de extrema urgência que o governo invista na educação de seus jovens, com parceria de professores e responsáveis [...]. (RED2019C02).

Nesse caso, para defender a alternativa de que é importante que o governo proponha ações com prontidão quanto ao bullying no ambiente escolar, o pré-universitário traz um exemplo de um acontecimento recente. Com isso, o estudante tenta apresentar um exemplo/caso particular com o viés de estabelecer e defender certas conclusões e apontar determinadas atitudes.

Outra estratégia argumentativa que se enquadra dentro da realidade, encontrada em nosso corpus, se caracteriza, dentre outros aspectos, por defender uma dada ação, levando em consideração os efeitos (positivos ou negativos) que ela venha a produzir. Para discorrer melhor sobre essa estratégia, vejamos o exemplo:

(12) Os pais precisam ter uma boa comunicação com os responsáveis pela escola, e também com os seus filhos, para que juntos eles possam controlar ou acabar de vez com a questão do bullying naquele determinado ambiente. (RED2019C03).

Em (12), conseguimos observar o que Perelman e Tyteca ([1958] 1996), p. 303) chamam de "argumento pragmático", que, como vimos na seção anterior, é utilizado quando "para apreciar um acontecimento, reportase a seus efeitos". Assim, encontramos no exemplo (12) um argumento pragmático, pois temos uma proposta que funcionaria como indicação de solução para o problema do bullying dentro do ambiente escolar. Assim, o estudante pré-universitário defende um maior diálogo entre pais, alunos e gestores, tendo em vista que essa ação geraria efeitos positivos no combate ao bullying.

Uma outra técnica argumentativa também presente em nosso corpus serve, segundo Fiorin (2018, p. 188), "para reforçar uma tese tida como aceita". Nesse sentido, temos o "argumento por ilustração", em que o locutor, para sustentar sua tese, não se volta à comprovação, mas procura a comoção como um modo argumentativo. Assim sendo, esse recurso argumentativo se constrói a partir da elaboração de uma breve narrativa, que pode ser real ou fictícia, tendo o intuito de concretizar aquilo que está sendo defendido na tese. Vejamos o exemplo (13):

(13) Infelizmente, não suportando mais as doses diárias de agressões, tanto físicas e psicológicas, uma das personagens cometeu suicídio. Situação essa retratada na série, presente no nosso cotidiano com uma assustável frequência. (RED2019C02).

No exemplo acima, a tese de que os tipos de violências gerados dentro do bullying podem levar ao suicídio toma por base uma ilustração que, por sua vez, propende-se para algo mais sentimental. Em (13), asserções como "não suportando doses diárias de agressões” buscam direcionar a uma comoção, ao retratar e ilustrar o fato de o agredido estar diariamente sofrendo violência. Nesse sentido, utilizando esse tipo de argumento, 
o estudante pré-universitário ainda resgata na memória possíveis casos de suicídio e reforça sua tese, considerada como aceita, através da comoção. Outrossim, o pré-universitário utilizou o seu argumento baseando-se no exemplo de um trecho de uma série: "uma das personagens cometeu suicídio", "situação essa retratada na série", ou seja, o argumento foi baseado a partir de uma narrativa fictícia de uma série, cuja temática principal era o bullying.

Os proponentes do Tratado da Argumentação ainda postularam sobre determinados argumentos que tratam como igual cada uma das partes que compõem o todo, ou seja, $a$ "inclusão da parte no todo". Essa técnica foi evidenciada em nosso corpus, como podemos observar em (14):

(14) Quando outras pessoas observam um senhor de idade mais avançada sendo vítima de tal ação e não procuram tomar uma atitude para ajudar, elas tornam-se cúmplices daquele ato. (RED2019C09).

A estratégia argumentativa utilizada em (14) inclui as partes em um todo. Nesse caso, apoiando-nos em Perelman e Tyteca ([1958] 1996), podemos dizer que o todo da situação referenciada pelo aluno é estruturado, ou seja, o todo é mais do que a soma das partes, pois temos uma diferença qualitativa entre as partes e o todo. A tese defendida pelo aluno está relacionada a uma determinada situação de violência: um idoso sendo vítima de agressão (o todo). Mas essa situação de agressão, na tese do aluno, é mais do que a soma do agressor com o agredido, porque podemos ter: agressor, agredido e cúmplice (as partes). Desse modo, o pré-universitário inclui como uma parte equivalente às outras partes de uma determinada situação de violência o indivíduo que, presenciando um ato de agressão, age de modo passivo, tornando-se conivente a tal atitude.

\section{CONCLUSÕES}

Este trabalho propôs uma análise voltada às técnicas argumentativas presentes em redações estilo ENEM. Assim, tendo em vista a importância dos projetos extensão para as universidades públicas e suas comunidades, formamos o nosso corpus a partir das redações produzidas dentro do Projeto de Extensão Palestras Interdisciplinares e Oficinas de Produção Textual para o ENEM (ProENEM/ UNILAB).

Por intermédio do estudo dos postulados teóricos a respeito das técnicas argumentativas — com base em Perelman e Tyteca ([1958] 1996), Fiorin (2018), Garantizado Júnior (2015) e Menezes (2011) — e da observação dos textos produzidos por estudantes do Curso de Redação Gratuito do ProENEM (UNILAB), realizado em Redenção-CE, foi possível constatarmos a presença de argumentos baseados na estrutura do real, argumentos que fundamentam a estrutura do real e os argumentos quase-lógicos.

Conforme o que resultou de nossa investigação, podemos afirmar que o objetivo de nosso trabalho foi alcançado, pois conseguimos observar que os estudantes pré-universitários do Curso de Redação do ProENEM (UNILAB), participando das oficinas realizadas por esse projeto de extensão, conseguem construir a argumentação em seus textos fazendo uso de variadas técnicas argumentativas para dar solidez ao ponto de vista defendido. 
É nessa perspectiva que ressaltamos, mais uma vez, a importância de projetos de extensão universitária que atendam às demandas da população. Essas iniciativas fazem a diferença ao possibilitarem a oportunidade da comunidade externa à universidade experienciar os saberes produzidos no ambiente acadêmico. Esse contato é importante para despertar nos estudantes das escolas públicas a ambição de ingressarem no ensino superior, pois a experiência ofertada pela extensão universitária os faz observar que seus sonhos podem estar mais acessíveis, visto que muitos alunos não aspiram o ensino universitário por acharem que é uma realidade distante.

Por esse motivo, é de suma importância a valorização dos projetos de extensão universitária. A realização desse Curso de Redação, totalmente gratuito, possuiu o objetivo social de oferecer aos pré-universitários da rede pública de ensino um conjunto de recursos que possibilitaram o aprimoramento dos seus conhecimentos acerca do texto dissertativo-argumentativo exigido pelo ENEM. Dessa forma, a partir de oficinas, correções de redação, palestras, rodas de conversa e cursos gratuitos de redação, o PROENEM/UNILAB busca incentivar esses estudantes ao ingresso na universidade pública.

Além disso, com a realização desse trabalho, conseguimos notar que é através da argumentação que o texto vai formando os seus fatores básicos. Dessa forma, fica a sugestão para trabalhos futuros que analisem como a sequência argumentativa pode propiciar fatores construtores de, por exemplo, coerência/coesão em textos dissertativo-argumentativos.

\section{REFERÊNCIAS}

FIORIN, José Luiz. Argumentação. São Paulo: Contexto, 2018.

GARANTIZADO JÚNIOR, José Olavo da Silva. Estudo da argumentação sob uma perspectiva textual e retórica. 2015. p. 176-183. Tese (Doutorado) - Universidade Federal do Ceará, Departamento de Letras Vernáculas, Programa de Pós-Graduação em Linguística, Fortaleza.

INEP. Resultados ENEM 2019. Brasília: INEP, 2020. Disponível em: <http://download.INEP.gov.br/ educacao_basica/ENEM/downloads/2019/apresentacao_resultados_ENEM_2019.pdf> Acesso em: 18 Jan. 2020.

LIMA, Edmar Peixoto de; OLIVEIRA, Flávia Cristina Cândido de; GARANTIZADO JÚNIOR, José Olavo da Silva. As técnicas argumentativas na redação do ENEM. Pontes Editores, 2018.

MEDEIROS, João Bosco. Redação Empresarial. - 7. ed.- São Paulo: Atlas, 2010. p. 125.

MENEZES, Léia Cruz de. Expressões linguísticas modalizadoras deônticas em função argumentativa: um exercício de análise retórico funcional. p. 37-44. Tese (Doutorado) - Universidade Federal do Ceará, Departamento de Letras Vernáculas, Programa de Pós-Graduação em Linguística, Fortaleza. 2011.

Ministério da Educação. Exame Nacional do Ensino Médio. Disponível em: <http://portal.mec.gov.br/enemsp-2094708791\#>. Acessado em 18 Jan. 2020. 
PERELMAN, Chaïm; OLBRECHTS-TYTECA, Lucie. Tratado da argumentação: a nova retórica. Trad. Maria Ermantina de Almeida Prado Galvão. São Paulo: Martins Fontes, 1996. (Trad. de Traité de lìArgumentation. La Nouvelle Rhétorique. Paris: PUF, 1958).

RODRIGUEZ, Ana Miriam Carneiro. Breve recurso dos estudos sobre argumentação. Memento: Revista de Linguagem, Cultura e Discurso. Mestrado em Letras. Unincor. Vol. O8, N.2. 2017.

THEREZO, Graciema Pires. Como corrigir redação. 7. ed. Campinas: Editora Alínea, 2012.

Submetido em: 06/01/2021 Aceito em: 29/03/2021. 